\title{
Identifying the predictors of estimated glomerular filtration rate after partial nephrectomy with a nonlinear regression model
}

\author{
Emre Karabay ${ }^{1}$, Cagatay Tosun $^{2}$, Nejdet Karsiyakali ${ }^{3}$, Kemal Kayar $^{2}$, Serdar Aykan², \\ Ahmet Ruknettin Aslan ${ }^{2}$, Omer Ergin Yucebas ${ }^{2}$, and Metin Ishak Ozturk ${ }^{2}$ \\ ${ }^{1}$ Istanbul Haydarpasa Numune Egitim ve Arastirma Hastanesi \\ ${ }^{2}$ İstanbul Haydarpaşa Numune Eğitim ve Araştırma Hastanesi \\ ${ }^{3}$ Acibadem Universitesi
}

June 22, 2020

\begin{abstract}
Purpose: To evaluate the effect of partial nephrectomy on renal function and to identify predictors of estimated glomerular filtration rate (eGFR) at six months after partial nephrectomy. Methods: Medical data of 154 consecutive patients who underwent partial nephrectomy for a renal mass between January 2015 and March 2020 were retrospectively analyzed. The primary outcome measure was eGFR at six months postoperatively. A non-linear regression analysis was performed to examine the association between primary outcome measure and candidate predictors. Results: Of the patients, 66 (42.9\%) were females and $88(57.1 \%)$ were males with a median age of 60 (range, 50 to 67) years. The median baseline eGFR was 90.40 (range, 74.96 to 102.97$) \mathrm{mL} / \mathrm{min} / 1.73 \mathrm{~m} 2$, while the median eGFR at six months was 77.12 (range, 61.06 to 91.93 ) $\mathrm{mL} / \mathrm{min} / 1.73 \mathrm{~m} 2$ $(\mathrm{p}<0.001)$. Baseline eGFR $(?=22.691,95 \%$ CI: 18.821 to 26.460 , when baseline eGFR levels change from $74.97 \mathrm{ml} / \mathrm{min} / 1.73 \mathrm{~m} 2$ to $102.68 \mathrm{ml} / \mathrm{min} / 1.73 \mathrm{~m} 2, \mathrm{p}<0.001$ ) was found to be directly associated with the postoperative eGFR levels at six months. In contrary, advanced tumor size $(?=-3.168,95 \% \mathrm{CI}$ : -5.332 to -1.005 , when tumor size levels change from 3 to $6 \mathrm{~cm}, \mathrm{p}<0.001)$ and presence of hypertension $(?=-3.479,95 \% \mathrm{CI}$ : -6.956 to $-0.0031, \mathrm{p}=0.049)$ were also found to be inversely associated with the postoperative eGFR levels at six months. Conclusion: Baseline eGFR values, tumor size, and presence of hypertension are significant predictors of eGFR values in the mid-term in patients undergoing partial nephrectomy.
\end{abstract}

Identifying the predictors of estimated glomerular filtration rate after partial nephrectomy with a nonlinear regression model

\section{Running Title: Predictors of eGFR after partial nephrectomy}

Authors: Emre Karabay ${ }^{1 *}$, Çăgatay Tosun ${ }^{1}$, Nejdet Karsiyakali ${ }^{2}$, Kemal Kayar ${ }^{1}$, Serdar Aykan ${ }^{1}$, Ahmet Ruknettin Aslan ${ }^{1}$, Omer Ergin Yucebas ${ }^{1}$, Metin Ishak Ozturk ${ }^{1}$

The authors' institutional affiliations:

${ }^{1}$ University of Health Sciences, Haydarpasa Numune Training and Research Hospital, Department of Urology, Istanbul, Turkey

${ }^{2}$ Acibadem M.A. Aydinlar University, Altunizade Hospital, Department of Urology, Istanbul, Turkey

*Corresponding Author:

Emre Karabay, MD

University of Health Sciences, Haydarpasa Numune Training and Research Hospital, Department of Urology, Istanbul, Turkey 
Address: Tıbbiye Cad. No: 23, PK: 34668, Üsküdar, Istanbul / TURKEY

Tel: +902165423232

E-mail: emrekarabay@gmail.com

ORCID ID:https://orcid.org/0000-0003-1654-8524

\section{Acknowledgments}

None

Conflict of interest: The authors declare that they have no conflict of interest.

Funding: None

\section{What's already known about this topic?}

- Partial nephrectomy is the gold standart treatment of small renal masses.

- The estimated glomerular filtration rate (eGFR) is a valuable marker of renal function in clinical practice.

- Even though partial nephrectomy protects kidney function better than radical nephrectomy, the factors affecting postoperative eGFR levels are worth to discuss.

\section{What does this article add?}

- We created a new model to predict mid-term renal function after partial nepfrectomy.

- This study shows that baseline eGFR, tumor size and hypertension are the strongest predictors for mid-term renal functions.

- This study would provide urologists an insight into the effect of partial nephrectomy on renal function and might be a useful guide for urologists to inform patients about mid-term renal function.

Identifying the predictors of estimated glomerular filtration rate after partial nephrectomy with a nonlinear regression model

Purpose: To evaluate the effect of partial nephrectomy on renal function and to identify predictors of estimated glomerular filtration rate (eGFR) at six months after partial nephrectomy.

Methods: Medical data of 154 consecutive patients who underwent partial nephrectomy for a renal mass between January 2015 and March 2020 were retrospectively analyzed. The primary outcome measure was eGFR at six months postoperatively. A non-linear regression analysis was performed to examine the association between primary outcome measure and candidate predictors.

Results: Of the patients, 66 (42.9\%) were females and 88 (57.1\%) were males with a median age of 60 (range, 50 to 67 ) years. The median baseline eGFR was 90.40 (range, 74.96 to 102.97 ) $\mathrm{mL} / \mathrm{min} / 1.73 \mathrm{~m}^{2}$, while the median eGFR at six months was 77.12 (range, 61.06 to 91.93$) \mathrm{mL} / \mathrm{min} / 1.73 \mathrm{~m}^{2}(\mathrm{p}<0.001)$. Baseline eGFR $(\beta$ $=22.691,95 \%$ CI: 18.821 to 26.460 , when baseline eGFR levels change from $74.97 \mathrm{ml} / \mathrm{min} / 1.73 \mathrm{~m}^{2}$ to 102.68 $\mathrm{ml} / \mathrm{min} / 1.73 \mathrm{~m}^{2}, \mathrm{p}<0.001$ ) was found to be directly associated with the postoperative eGFR levels at six months. In contrary, advanced tumor size ( $\beta=-3.168,95 \%$ CI: -5.332 to -1.005 , when tumor size levels change from 3 to $6 \mathrm{~cm}, \mathrm{p}<0.001)$ and presence of hypertension $(\beta=-3.479,95 \% \mathrm{CI}$ : -6.956 to $-0.0031, \mathrm{p}=0.049)$ were also found to be inversely associated with the postoperative eGFR levels at six months.

Conclusion: Baseline eGFR values, tumor size, and presence of hypertension are significant predictors of eGFR values in the mid-term in patients undergoing partial nephrectomy.

Keywords: renal cell carcinoma; glomerular filtration rate; partial nephrectomy; predictor; renal failure

\section{Introduction}

Renal cell carcinoma (RCC) is one of the most common neoplasms of the genitourinary system which accounts for about $3 \%$ of all neoplasms in adults [1]. In parallel with the widespread use of abdominal 
imaging modalities, the incidence of small renal masses (SRMs) which are diagnosed incidentally has been increasing recently [2]. Currently, surgery is the gold-standard treatment of SRMs and partial nephrectomy $(\mathrm{PN})$ is the recommended procedure, if technically possible [3]. It has similar oncological outcomes as radical nephrectomy, and observational studies have demonstrated that $\mathrm{PN}$ offers better preservation of kidney function and increased overall survival in selected patients [4-6].

Partial nephrectomy, also known as nephron-sparing surgery (NSS), has been increasingly used in clinical practice as a standard procedure in patients with localized SRMs; however, it has been shown to be associated with postoperative renal failure [7,8]. Although several studies have examined the effect of PN on renal function including tumor characteristics, surgical techniques, and comorbidities of patients, there is still an unmet need for further studies identifying predictors of postoperative renal function [8-11].

The estimated glomerular filtration rate (eGFR) is a valuable marker of renal function in clinical practice. Decreased eGFR has been shown to be associated with increased overall mortality, need for hospitalization, and cardiovascular disease [12]. In the present study, we aimed to evaluate the effect of PN on renal function and to identify predictors of eGFR at mid-term in patients with a renal mass.

\section{Materials and Methods}

Study design and study population

This longitudinal, retrospective study was conducted at University of Health Sciences, XXX, Urology outpatient clinic between January 2015 and March 2020. The study protocol was approved by the institutional Ethics Committee. The study was conducted in accordance with the principles of the Declaration of Helsinki. Medical data of 201 consecutive patients who underwent PN for a renal mass were retrospectively reviewed. All data were retrieved from the hospital database. Those having a bilateral renal mass $(\mathrm{n}=5)$, multiple tumors in the same kidney $(\mathrm{n}=3)$, tumors in solitary kidney $(\mathrm{n}=5)$, missing data in the hospital database $(\mathrm{n}=26)$, and not attending to their scheduled follow-up visit at six months $(\mathrm{n}=8)$ were excluded from the study. Finally, a total of 154 consecutive patients who were treated with open or laparoscopic PN were included.

Surgical procedure

All surgical procedures were performed by four urologists experienced in uro-oncology under general anesthesia. As a standard procedure, the renal artery and vein were secured with vascular clips after renal pedicle dissection. The surrounding adipose tissue and Gerota's fascia of the renal mass were dissected and the parenchymal margins were well demarcated. The decision of warm ischemia was made at this stage, depending on the localization and size of the tumor. In all cases, tumors were excised, instead of the enucleation procedure, and a base suture layer was placed followed by a horizontal mattress cortical renorrhaphy. Pathological specimens were evaluated by two experienced uropathologists.

Measurements and definitions of variables

Data including demographic and clinical characteristics of the patients were obtained from the hospital database. Patients with diabetes mellitus (DM) and hypertension (HT) were defined as those treated with medical anti-diabetic and antihypertensive treatments at the time of enrollment, respectively.

Anatomical features of the tumors were examined using the preoperative contrast-enhanced computed tomography (CT) or magnetic resonance imaging (MRI) scans. The tumor volume was calculated using the following formula: $\pi / 6 \mathrm{x}$ the longest axial diameter $\mathrm{x}$ the longest coronal diameter $\mathrm{x}$ the longest sagittal diameter. The Preoperative Aspects and Dimensions Used for an Anatomical (PADUA) score was determined from CT or MRI scans by two urologists, as described by Ficarra et al. [13]. Duration of warm ischemia was defined as the time from clamping of the renal artery alone or in combination with the renal vein during surgery.

The eGFR values were calculated using the Modification of Diet in Renal Disease (MDRD) formula as previously described: $186 \times$ (Creatinine/88.4)-1.154 x (Age)-0.203 x (0.742 if female) $\times$ (1.210 if black) 
and chronic kidney disease (CKD) stages were defined according to the definition of the National Kidney Foundation (NKF) [14]. Baseline eGFR values were calculated using the creatinine values at the final preoperative visit. In the outpatient follow-up visit at six months, creatinine values were re-calculated and the eGFR values were determined and documented in detail.

\section{Statistical Analysis}

The primary outcome measure was the postoperative eGFR at six months. Variables included in the statistical analysis according to prior evidence of clinical and/or biological association with eGFR were identified. Candidate predictors included age, baseline eGFR, DM, HT, body mass index (BMI), surgery type, tumor size, tumor volume, PADUA score, warm ischemia time (WIT), sex, tumor localization, and the American Society of Anesthesiologists (ASA) class.

Statistical analysis was performed using the $\mathrm{R}$ software version 3.5.1 (Institute for Statistics and Mathematics, Vienna, Austria). Continuous variables were expressed in median and interquartile range (IQR), while categorical variables were expressed in number and percentage. A non-linear regression analysis was used to examine the correlation between the primary outcome measure and candidate predictors. The number of predictors for creating a regression model was determined by at least 1:10 rule of thumb due to overfitting risk. The correlation between candidate predictors and study outcomes were described as regression coefficient $(\beta)$ and standard error (SE). The likelihood ratio and chi-square tests were used to assess the goodness-of-fit of the model and the $R^{2}$ was used to examine the predictive ability of the model. A two-sided $p$ value of $<0.05$ was considered statistically significant.

\section{Results}

Of a total of 154 patients, $66(42.9 \%)$ were females and $88(57.1 \%)$ were males with a median age of 60 (range, 50 to 67 ) years. Demographic and clinical characteristics and pathological results and stages of the tumor are summarized in Table 1. A total of 87 (56.5\%) patients underwent open PN, while 67 (43.5\%) patients underwent laparoscopic PN. The median duration of surgery, WIT, and length of hospital stay were 150 (range, 120 to 180) $\mathrm{min}, 16$ (range, 10 to 18) $\mathrm{min}$, and 4 (range, 3 to 5) days, respectively. In total, 13 (8.4\%) patients required blood transfusion, while a double $\mathrm{J}$ stent $\left(4.8-\mathrm{Ch} / \mathrm{Fr}, 28 \mathrm{~cm}\right.$, Coloplast ${ }^{\circledR}$, Humlebæk, Denmark) was deployed in seven (4.5\%) patients due to urine leak.

The median baseline eGFR was 90.40 (range, 74.96 to 102.97 ) $\mathrm{mL} / \mathrm{min} / 1.73 \mathrm{~m}^{2}$, while the median eGFR at six months was 77.12 (range, 61.06 to 91.93$) \mathrm{mL} / \mathrm{min} / 1.73 \mathrm{~m}^{2}(\mathrm{p}<0.001)$. The change from baseline at six months for each patient (Figure 1a) and for overall study population(Figure 1b) are schematized in Figure 1 . According to baseline eGFR values, 23 (14.9\%) patients had Grade [?]IIIa CKD (eGFR [?]60 $\mathrm{mL} / \mathrm{min} / 1.73 \mathrm{~m}^{2}$ ), while the number of these patients increased to $37(24 \%)$ at the postoperative sixth month.

The tumor volume was statistically significantly lower and duration of surgery was statistically significantly shorter in the patients undergoing laparoscopic PN than open surgery ( $\mathrm{p}=0.028$ and $\mathrm{p}=0.003$, respectively). The tumor volume was statistically significantly higher and duration of surgery was statistically significantly longer in patients receiving warm ischemia than those without ( $\mathrm{p}=0.02$ and $\mathrm{p}=0.021$, respectively). No significant difference in the surgical margin positivity rate between the patients undergoing open $(\mathrm{n}=4$, $4.6 \%)$ and laparoscopic $(\mathrm{n}=4,6.0 \%) \mathrm{PN}(\mathrm{p}=0.705$ for both).

The non-linear regression model was used to identify the correlation between eGFR values at six months and candidate predictors. The goodness of fit of the model according to observed and expected eGFR values was evaluated using the calibration plot. Accordingly, the model was found to be highly consistent in predicting eGFR values at the postoperative sixth month (likelihood ratio- $\left.\chi 2=347.52, R^{2}=0.895\right)$ (Figure 2 ). Baseline eGFR ( $\beta=22.691,95 \%$ CI: 18.821 to 26.460 , when baseline eGFR levels change from $74.97 \mathrm{ml} / \mathrm{min} / 1.73 \mathrm{~m}^{2}$ to $102.68 \mathrm{ml} / \mathrm{min} / 1.73 \mathrm{~m}^{2}, \mathrm{p}<0.001$ ) was found to be directly associated with the postoperative eGFR levels at six months. In contrary, advanced tumor size $(\beta=-3.168,95 \% \mathrm{CI}$ : -5.332 to -1.005 , when tumor size levels change from 3 to $6 \mathrm{~cm}, \mathrm{p}<0.001)$ and presence of hypertension $(\beta=-3.479,95 \% \mathrm{CI}$ : -6.956 to -0.0031 , 
$\mathrm{p}=0.049$ ) were also found to be inversely associated with the postoperatif eGFR levels at six months (Table 2 and Figure 3 ). The partial effect plots of significant predictors are shown inFigure 4 .

\section{Discussion}

In the current study, we evaluated the effect of PN on renal function and identified predictors of eGFR at six months in patients with a renal mass. Our study results showed a statistically significant decrease in the eGFR values at six months compared to baseline in PN patients. The non-linear regression analysis model also revealed a linear relationship between the baseline eGFR and six-month eGFR values, while there was an inverse relationship between the tumor size and presence of HT and six-month eGFR values.

In the literature, there is an abundant number of studies investigating the factors affecting CKD development following PN. In the majority of studies, the primary endpoint for the evaluation of renal function is the development of CKD according to the NKF's CKD stages based on eGFR values $[15,16]$. However, NSS provides preservation of the renal function in most patients with a renal mass and disease progression ratio is about 10 to $20 \%$ in Grade [?]IIIa CKD [17,18]. In addition, Turin et al. [19] reported that patients with a decline of [?]5 mL/min/1.73 $\mathrm{m}^{2}$ per year had two-fold increased risk for mortality (adjusted HR 1.52; 95\% CI: 1.46 to 1.57). In another study, Matsushita et al. [20] found that an annual decline of [?]5.65\% in eGFR values increased the risk of chronic heart disease by 1.3 folds and all-cause mortality by 1.22 folds. Therefore, the number of studies evaluating longitudinal change in eGFR values rather than binary cut points and investigating predictors of eGFR in patients undergoing PN has been increasing in recent years [21-24]. In our study, $14(9 \%)$ patients developed Grade [?]IIIa CKD following PN and the median postoperative eGFR values decreased by $10.98 \mathrm{~mL} / \mathrm{min} / 1.73 \mathrm{~m}^{2}$. Although the number of patients in whom Grade [?]IIIa CKD developed seems to be consistent with the existing literature, it is more realistic to speculate that the risk of chronic heart disease and all-cause mortality increases in these patients based on the eGFR decline postoperatively.

In their study including 1,379 RCC patients treated with radical nephrectomy or PN, Mason et al. [7] reported that the decline in eGFR values after three months remained stable in the PN arm. In addition, preoperative decreased renal function, advanced age, and increased tumor length were found to be associated with decreased eGFR values at the postoperative third month. In another study, Shum et al. [22] constructed two nomograms which could predict eGFR at one year after PN and found the preoperative serum creatinine level to be the only strong determinant of postoperative renal function. Similarly, in a recent study, Ficarra et al. [25] evaluated the ability of original tumor contact surface area to predict postoperative complications and renal function impairment in patients undergoing PN for renal masses and showed that preoperative eGFR was the independent predictor of absolute change ([?]10\%) in postoperative eGFR. Based on these findings, it is not unexpected that patients with decreased renal function have poor eGFR values during follow-up and that preoperative renal function is the most significant predictor of renal failure or eGFR decline. It is well-known that PN has no ability to restore renal function, although it preserves nephrons. Consistent with previous studies, we also found that preoperative eGFR value was the most significant predictor of postoperative eGFR values at six months.

Furthermore, Cha et al. [26] evaluated the effects of radiographic parameters of renal tumors on long-term renal function after PN and reported that the increased tumor volume was significantly associated with poor renal function in the long-term. In addition, Nisen et al. [27] compared anatomical classification systems to predict changes in postoperative renal function. The authors found that the PADUA predicted at least a $20 \%$ decline in GFR (OR: 1.55, $\mathrm{p}=0.021$ ) at the postoperative third month in patients with a renal mass of [?]3 $\mathrm{cm}$. Similarly, we used PADUA score and tumor volume as candidate predictors in our study. Unlike previous studies, however, neither candidate predictors increased the explanatory power of the model. As the tumor size is more practical than PADUA score and tumor volume in clinical practice, we included the tumor size in the model. The majority of renal masses were exophytic and SRMs in our study and, therefore, the PADUA score and tumor volume may not have increased the explanatory power of the model. Of note, consistent with our findings, there are reports in the literature suggesting that advanced tumor size is an independent risk factor of decreased renal function after PN $[12,21]$. As shown in the partial effect plots, the 
determinant effect of the tumor size increases, when the tumor size exceeds $4 \mathrm{~cm}$ corresponding to clinical Stage T1b.

The WIT is one of the most discussed topics in the literature. Although some authors have proposed that prolonged ischemia duration ( $>25 \mathrm{~min}$ ) adversely affects the postoperative renal function [28-30], there is no evidence showing that short ischemia duration significantly decreases renal function compared to zero ischemia [31]. Consistent with previous findings, WIT was not found to be a significant determinant in our model. This can be attributed to the fact that $24 \%$ of our patients received non-ischemic PN and the WIT was within acceptable ranges. In their study, Marszalek et al. [32] compared laparoscopic PN and open PN and found no significant difference in the oncological and functional outcomes between the surgery groups. However, the duration of surgery, duration of ischemia, and length of hospital stay were shorter in the laparoscopic PN patients. In our study, although the duration of surgery was shorter in the laparoscopic PN group, the WIT and length of hospital stay were comparable between the groups.

Review of the literature reveals controversial results regarding the effect of $\mathrm{HT}$ on renal function after PN. Consistent with our findings, in a retrospective study evaluating renal function after PN and radical nephrectomy, multivariate analysis showed that the presence of HT was associated with decreased renal function in the long-term in PN patients [21]. In another study, perioperative risk factors related to acute kidney injury after PN were included in a linear model which demonstrated that the presence of preoperative HT was associated with postoperative acute kidney injury [33]. On the contrary, Beksac et al. [34] found that HT and DM were not associated with poor renal functional outcome following robotic PN in patients with cT1 disease and normal preoperative renal function (eGFR [?]60 mL/min/1.73 $\mathrm{m}^{2}$ ). Similarly, another study investigating progression to CKD in patients undergoing PN for renal tumors showed that the presence of comorbidities such as coronary artery disease, DM, or HT was not a significant independent predictor of an increased risk of higher CKD stage in the long-term (ranging 3 to 18 months) [15]. The discrepancy in the results of the studies can be attributed to the utilization of different surgical methods, heterogeneous demographic and clinical characteristics of the study populations, statistical methods and models used, and the inclusion of different primary outcome measures or endpoints in the evaluation of CKD. Irrespective of the cause of difference, several factors play a role in renal function following PN, as evidenced by previous studies and our study. Currently, it has been well established that even slight changes in the eGFR values may increase the risk of cardiovascular disease and all-cause mortality. Therefore, we believe that further studies using prediction models would be useful to obtain a more accurate and holistic understanding of postoperative renal function in patients with renal masses.

Nonetheless, there are some limitations to this study. First, retrospective design of the study may have precluded the elimination of unknown confounders. Second, we included the eGFR values at six months postoperatively as the outcome measure in the model and used baseline eGFR as the only variable and we were unable to further evaluate albuminuria or eGFR using 24-h urine collection or scintigraphy. However, the main strengths of the present study are that it is one of the rare studies using a prognostic model for eGFR values following PN and it can identify predictors of eGFR. Owing to the strength of the prediction model used in our study, we believe that the results of this study are valuable and clinically relevant.

\section{Conclusion}

In conclusion, our study results suggest that low baseline eGFR values, advanced tumor size, and presence of HT are significant predictors of decreased eGFR values at the postoperative sixth month in patients undergoing PN for a renal mass. Despite the strength of the model used in our study, further multi-center, large-scale, and prospective studies are needed to confirm and to measure the external validity of the results. Nevertheless, we believe that these results would provide urologists an insight into the effect of PN on renal function and be a useful guide for urologists to inform patients about mid-term renal function before surgery and to decide the surgical approach for renal masses.

\section{Figure Legends}

Figure 1a. The box plot of change from baseline in eGFR values at Month 6 for each patient 
Figure 1b. Density plot of baseline eGFR and eGFR at Month 6 (overall population)

Figure 2. Calibration plot of the model for predict to eGFR at Month 6

Figure 3 . Forest plot of all candidate predictors in full model (Adjusted eGFR $=60$, male, age $=60$ )

Figure 4. Partial effect plots of strongest predictors for predict to eGFR at Month 6 (Adjusted according to median values)

\section{Declarations}

\section{Acknowledgments}

None

Conflict of interest: The authors declare that they have no conflict of interest.

\section{Funding: None}

Author contributions: EK: Conceptualization, Formal Analysis, Investigation, Methodology, Project administration, Validation, Visualization, Writing - original draft; ÇT:Conceptualization, Methodology, Project administration, Supervision;NK: Formal Analysis, Investigation, Writing - original draft;KK: Data curation, Resources; SA: Data curation, Investigation; ARA: Conceptualization, Methodology, Supervision; OEY: Writing - review \& editing; MIO:Supervision, Writing - review \& editing. All authors read and approved the final version of the manuscript.

\section{References}

1. Ferlay J, Steliarova-Foucher E, Lortet-Tieulent J, Rosso S, Coebergh JW, Comber H, Forman D, Bray F (2013) Cancer incidence and mortality patterns in Europe: estimates for 40 countries in 2012. Eur J Cancer 49 (6):1374-1403. doi:10.1016/j.ejca.2012.12.027

2. Gill IS, Aron M, Gervais DA, Jewett MA (2010) Clinical practice. Small renal mass. N Engl J Med 362 (7):624-634. doi:10.1056/NEJMcp0910041

3. Campbell SC, Novick AC, Belldegrun A, Blute ML, Chow GK, Derweesh IH, Faraday MM, Kaouk JH, Leveillee RJ, Matin SF (2009) Guideline for management of the clinical T1 renal mass. The Journal of urology 182 (4):1271-1279

4. MacLennan S, Imamura M, Lapitan MC, Omar MI, Lam TB, Hilvano-Cabungcal AM, Royle P, Stewart F, MacLennan G, MacLennan SJ, Canfield SE, McClinton S, Griffiths TR, Ljungberg B, N'Dow J (2012) Systematic review of oncological outcomes following surgical management of localised renal cancer. Eur Urol 61 (5):972-993. doi:10.1016/j.eururo.2012.02.039

5. Lau WK, Blute ML, Weaver AL, Torres VE, Zincke H (2000) Matched comparison of radical nephrectomy vs nephron-sparing surgery in patients with unilateral renal cell carcinoma and a normal contralateral kidney. Mayo Clin Proc 75 (12):1236-1242. doi:10.4065/75.12.1236

6. Miller DC, Hollingsworth JM, Hafez KS, Daignault S, Hollenbeck BK (2006) Partial nephrectomy for small renal masses: an emerging quality of care concern? J Urol 175 (3 Pt 1):853-857; discussion 858. doi:10.1016/s0022-5347(05)00422-2

7. Mason R, Kapoor A, Liu Z, Saarela O, Tanguay S, Jewett M, Finelli A, Lacombe L, Kawakami J, Moore R, Morash C, Black P, Rendon RA (2016) The natural history of renal function after surgical management of renal cell carcinoma: Results from the Canadian Kidney Cancer Information System. Urol Oncol 34 (11):486.e481-486.e487. doi:10.1016/j.urolonc.2016.05.025

8. Sun M, Bianchi M, Hansen J, Trinh QD, Abdollah F, Tian Z, Sammon J, Shariat SF, Graefen M, Montorsi F, Perrotte P, Karakiewicz PI (2012) Chronic kidney disease after nephrectomy in patients with small renal masses: a retrospective observational analysis. Eur Urol 62 (4):696-703. doi:10.1016/j.eururo.2012.03.051 
9. Wang Z, Liu C, Chen R, Liu S, Feng C, Yu K, Zeng X (2018) Will the kidney function be reduced in patients with renal cell carcinoma following laparoscopic partial nephrectomy? Baseline eGFR, warm ischemia time, and RENAL nephrometry score could tell. Urol Oncol 36 (11):498.e415-498.e424. doi:10.1016/j.urolonc.2018.08.007

10. Thompson RH, Lane BR, Lohse CM, Leibovich BC, Fergany A, Frank I, Gill IS, Blute ML, Campbell SC (2012) Renal function after partial nephrectomy: effect of warm ischemia relative to quantity and quality of preserved kidney. Urology 79 (2):356-360. doi:10.1016/j.urology.2011.10.031

11. Guo J, Zhou X, Zhang C, Wang G, Fu B (2020) Comparison Studies of "Ultrathin Parenchyma" Resection and Sharp Dissection in Robotic Partial Nephrectomy for Renal Tumors. J Endourol 34 (3):281-288. doi:10.1089/end.2019.0698

12. Go AS, Chertow GM, Fan D, McCulloch CE, Hsu CY (2004) Chronic kidney disease and the risks of death, cardiovascular events, and hospitalization. N Engl J Med 351 (13):1296-1305. doi:10.1056/NEJMoa041031

13. Ficarra V, Novara G, Secco S, Macchi V, Porzionato A, De Caro R, Artibani W (2009) Preoperative aspects and dimensions used for an anatomical (PADUA) classification of renal tumours in patients who are candidates for nephron-sparing surgery. Eur Urol 56 (5):786-793. doi:10.1016/j.eururo.2009.07.040

14. Levey AS, Coresh J, Greene T, Stevens LA, Zhang YL, Hendriksen S, Kusek JW, Van Lente F (2006) Using standardized serum creatinine values in the modification of diet in renal disease study equation for estimating glomerular filtration rate. Ann Intern Med 145 (4):247-254. doi:10.7326/0003-4819-145-4-20060815000004

15. Clark MA, Shikanov S, Raman JD, Smith B, Kaag M, Russo P, Wheat JC, Wolf JS, Jr., Matin SF, Huang WC, Shalhav AL, Eggener SE (2011) Chronic kidney disease before and after partial nephrectomy. J Urol 185 (1):43-48. doi:10.1016/j.juro.2010.09.019

16. Huang WC, Levey AS, Serio AM, Snyder M, Vickers AJ, Raj GV, Scardino PT, Russo P (2006) Chronic kidney disease after nephrectomy in patients with renal cortical tumours: a retrospective cohort study. Lancet Oncol 7 (9):735-740. doi:10.1016/s1470-2045(06)70803-8

17. Simmons MN, Hillyer SP, Lee BH, Fergany AF, Kaouk J, Campbell SC (2012) Functional recovery after partial nephrectomy: effects of volume loss and ischemic injury. J Urol 187 (5):1667-1673. doi:10.1016/j.juro.2011.12.068

18. Mir MC, Campbell RA, Sharma N, Remer EM, Simmons MN, Li J, Demirjian S, Kaouk J, Campbell SC (2013) Parenchymal volume preservation and ischemia during partial nephrectomy: functional and volumetric analysis. Urology 82 (2):263-268. doi:10.1016/j.urology.2013.03.068

19. Turin TC, Coresh J, Tonelli M, Stevens PE, de Jong PE, Farmer CK, Matsushita K, Hemmelgarn BR (2013) Change in the estimated glomerular filtration rate over time and risk of all-cause mortality. Kidney Int 83 (4):684-691. doi:10.1038/ki.2012.443

20. Matsushita K, Selvin E, Bash LD, Franceschini N, Astor BC, Coresh J (2009) Change in estimated GFR associates with coronary heart disease and mortality. J Am Soc Nephrol 20 (12):2617-2624. doi:10.1681/asn.2009010025

21. Bhindi B, Lohse CM, Schulte PJ, Mason RJ, Cheville JC, Boorjian SA, Leibovich BC, Thompson RH (2019) Predicting Renal Function Outcomes After Partial and Radical Nephrectomy. Eur Urol 75 (5):766-772. doi:10.1016/j.eururo.2018.11.021

22. Shum CF, Bahler CD, Cary C, Masterson TA, Boris RS, Gardner TA, Kaimakliotis HZ, Foster RS, Bihrle R, Koch MO, Slaven JE, Jr., Sundaram CP (2017) Preoperative Nomograms for Predicting Renal Function at 1 Year After Partial Nephrectomy. J Endourol 31 (7):711-718. doi:10.1089/end.2017.0184 
23. Song C, Bang JK, Park HK, Ahn H (2009) Factors influencing renal function reduction after partial nephrectomy. J Urol 181 (1):48-53; discussion 53-44. doi:10.1016/j.juro.2008.09.030

24. Mir MC, Ercole C, Takagi T, Zhang Z, Velet L, Remer EM, Demirjian S, Campbell SC (2015) Decline in renal function after partial nephrectomy: etiology and prevention. J Urol 193 (6):1889-1898. doi:10.1016/j.juro.2015.01.093

25. Ficarra V, Crestani A, Bertolo R, Antonelli A, Longo N, Minervini A, Novara G, Simeone C, Carini M, Mirone V, Porpiglia F (2019) Tumour contact surface area as a predictor of postoperative complications and renal function in patients undergoing partial nephrectomy for renal tumours. BJU Int 123 (4):639-645. doi:10.1111/bju. 14567

26. Cha EK, Ng CK, Jeun B, Dunning A, Reifsnyder JE, DiPietro JR, Mazumdar M, Shih G, Auh YH, Del Pizzo JJ, Shariat SF, Scherr DS (2013) Preoperative radiographic parameters predict long-term renal impairment following partial nephrectomy. World J Urol 31 (4):817-822. doi:10.1007/s00345-011-0694-z

27. Nisen H, Heimonen P, Kenttä L, Visapää H, Nisen J, Taari K (2015) Renal tumour anatomical characteristics and functional outcome after partial nephrectomy. Scand J Urol 49 (3):193-199. doi:10.3109/21681805.2014.978819

28. Tachikake T, Shigeta M, Mita K, Marukawa K, Usui T, Ito K (2009) Decrease of renal function due to warm ischemia after laparoscopic partial nephrectomy: evaluation using 99mTc-DMSA renal scintigraphy. Urol Int 82 (2):162-165. doi:10.1159/000200792

29. Pouliot F, Pantuck A, Imbeault A, Shuch B, Calimlim B, Audet JF, Finley DS, Dujardin T (2011) Multivariate analysis of the factors involved in loss of renal differential function after laparoscopic partial nephrectomy: a role for warm ischemia time. Can Urol Assoc J 5 (2):89-95. doi:10.5489/cuaj.10044

30. Thompson RH, Lane BR, Lohse CM, Leibovich BC, Fergany A, Frank I, Gill IS, Blute ML, Campbell SC (2010) Every minute counts when the renal hilum is clamped during partial nephrectomy. Eur Urol 58 (3):340-345. doi:10.1016/j.eururo.2010.05.047

31. Rod X, Peyronnet B, Seisen T, Pradere B, Gomez FD, Verhoest G, Vaessen C, De La Taille A, Bensalah K, Roupret M (2016) Impact of ischaemia time on renal function after partial nephrectomy: a systematic review. BJU Int 118 (5):692-705. doi:10.1111/bju.13580

32. Marszalek M, Meixl H, Polajnar M, Rauchenwald M, Jeschke K, Madersbacher S (2009) Laparoscopic and open partial nephrectomy: a matched-pair comparison of 200 patients. Eur Urol 55 (5):1171-1178. doi:10.1016/j.eururo.2009.01.042

33. Rajan S, Babazade R, Govindarajan SR, Pal R, You J, Mascha EJ, Khanna A, Yang M, Marcano FD, Singh AK, Kaouk J, Turan A (2016) Perioperative factors associated with acute kidney injury after partial nephrectomy. Br J Anaesth 116 (1):70-76. doi:10.1093/bja/aev416

34. Beksac AT, Reddy BN, Martini A, Paulucci DJ, Moshier E, Abaza R, Eun DD, Hemal AK, Badani KK (2019) Hypertension and diabetes mellitus are not associated with worse renal functional outcome after partial nephrectomy in patients with normal baseline kidney function. Int J Urol 26 (1):120-125. doi:10.1111/iju.13819

\section{Hosted file}

Table 1.docx available at https://authorea.com/users/313373/articles/461126-identifyingthe-predictors-of-estimated-glomerular-filtration-rate-after-partial-nephrectomy-with-anonlinear-regression-model

\section{Hosted file}

Table 2.docx available at https://authorea.com/users/313373/articles/461126-identifyingthe-predictors-of-estimated-glomerular-filtration-rate-after-partial-nephrectomy-with-a- 
nonlinear-regression-model
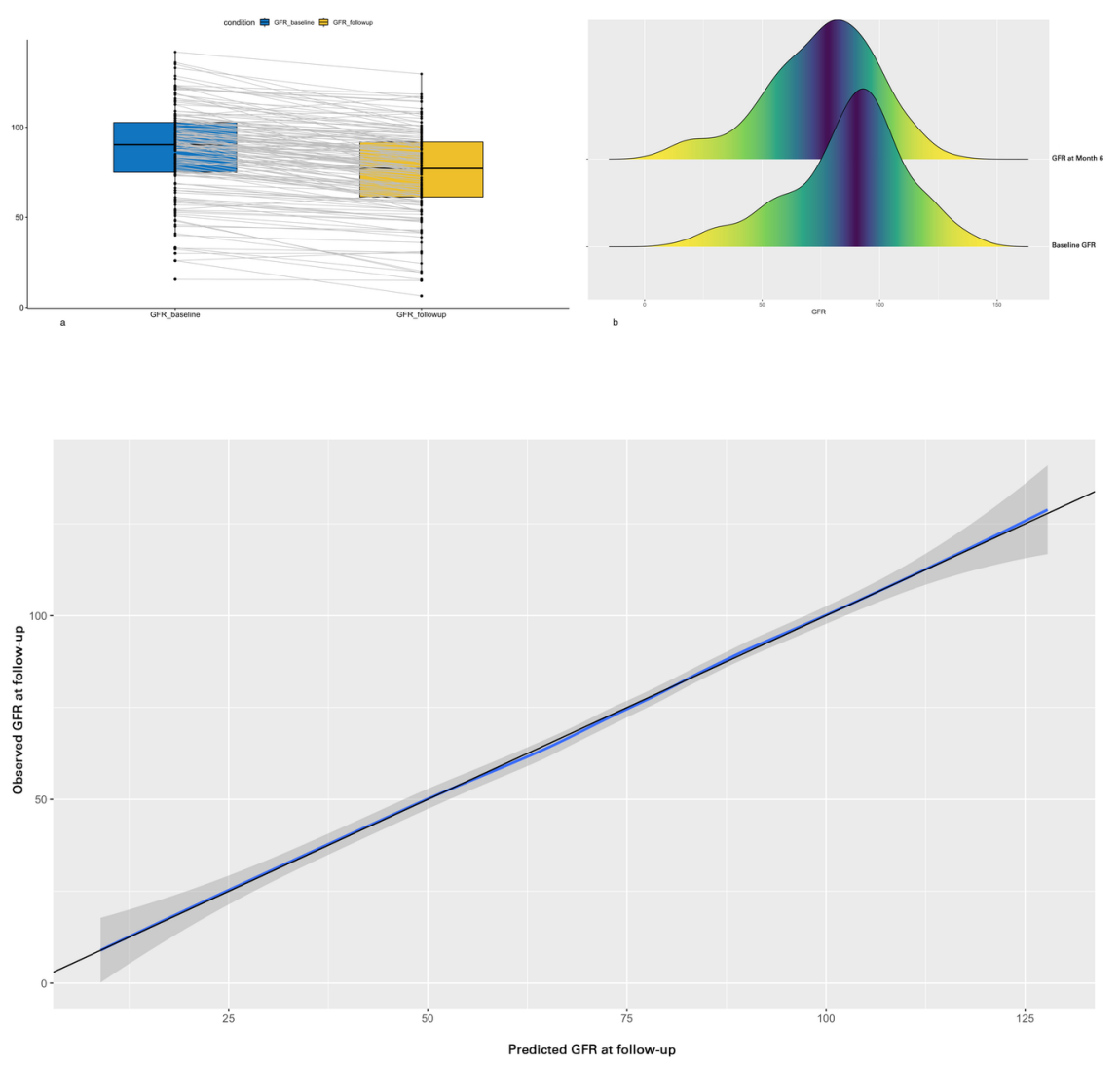

GFR_followup

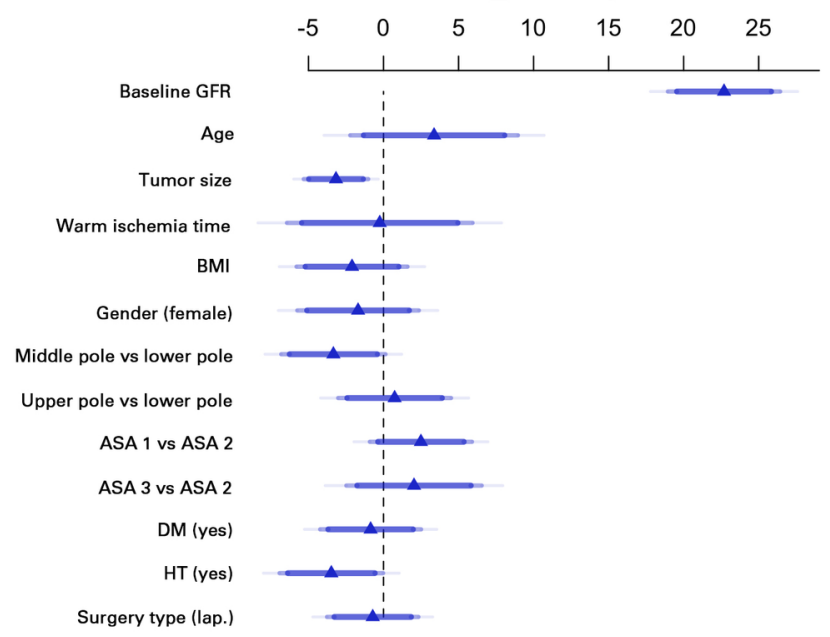




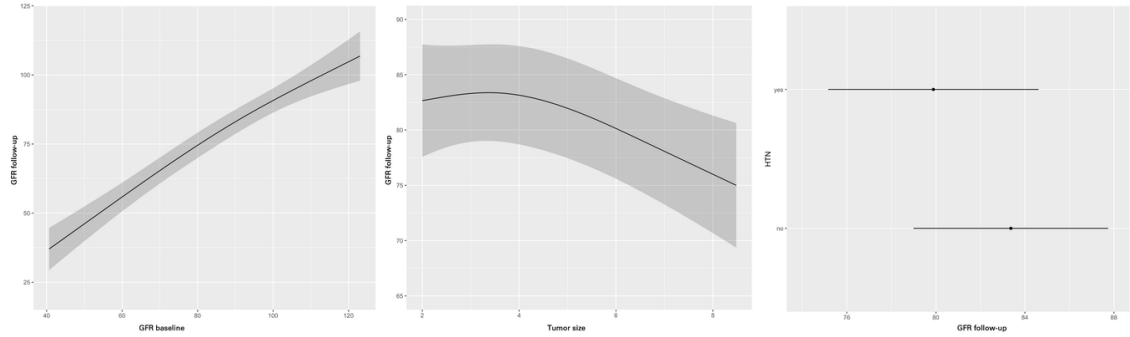

